\title{
HIV/AIDS Awareness, Attitudes and Risk Behavior Among University Students in Wuhan, China
}

\author{
Madelene Albrektsson ${ }^{1}$, Louise Alm ${ }^{1}$, Xiaodong $\operatorname{Tan}^{2}$ and Rune Andersson ${ }^{*}, 1,3$ \\ ${ }^{I}$ Department of Infectious Diseases, Institute of Biomedicine, Sahlgrenska Academy, University of Gothenburg, \\ Gothenburg, Sweden \\ ${ }^{2}$ School of Public Health, Wuhan University, Wuhan, China \\ ${ }^{3}$ Research and Development Centre, Skaraborg Hospital, Skövde, Sweden
}

\begin{abstract}
Background: In China, the estimated number of HIV positives in 2007 was 700,000 and the epidemic continues to expand. Because of their attitudes towards sexual behavior, young people are considered to be a group at high risk.

Methods: Eight hundred sixty-eight undergraduate students at Wuhan University were selected through stratified cluster sampling, to answer a questionnaire. They were divided into three main groups: Chinese medical students, foreign medical students and Chinese students from other faculties. Fourteen interviews were conducted in addition.

Results: Ninety-nine percent of the students had heard of HIV/AIDS and $76 \%$ of the students could distinguish HIV from AIDS. The main route of transmission was believed by the Chinese students to be blood transfusion and sexual intercourse by the foreign medical students. The female students knew more about the routes of transmission than the male students. Medical students had a higher level of knowledge than non-medical students, and among the medical students, the foreign students were more knowledgeable than the Chinese students. Only $8 \%$ of the students were sexually active.
\end{abstract}

Conclusion: The students had an accepting attitude towards people living with HIV and no extensive risk behavior. Overall, the knowledge level was found to be moderate.

Keywords: HIV, AIDS, information, epidemic, ethnic.

\section{INTRODUCTION}

\section{HIV and AIDS in China}

The first case of HIV in China was reported in 1985. The first epidemic spread began in 1989 among injecting drug users in rural areas. Since 1998 all 31 provinces, autonomous regions and municipalities have reported cases of HIV [1]. At the end of October 2007 the reported number of HIV positives was 223,501; including 62,838 cases of AIDS, while by the end of 2007 the estimated number of HIV positives was 700,000 (range $550,000-850,000$ ). This means that the HIV prevalence in China is 0.05 per cent. In comparison with other countries, the overall prevalence rate in China is still low but the epidemic continues to expand. The pace of the expansion has begun to slow down. In 2007, the estimated number of new infections was 50,000 [2]. According to calculations made by UNAIDS in 2000, the number of people infected in China might be as high as 10 million by 2010 [3] The Chinese government has taken actions to control the spread; the goal is to limit the number of HIV cases to 1.5 million in 2010 [4].

During the last few years the main route of transmission has changed from injecting drug users to heterosexual

*Address correspondence to this author at the Research and Development Centre, Skaraborg Hospital, SE-541 85 Skövde, Sweden; Tel: +46 500431137; Fax: +46 500 431121; E-mail: rune.andersson@vgregion.se transmission [2,5]. A contributing factor to the increased heterosexual transmission is a change of attitude towards sexuality in China. Since the declaration of the One Child Family policy, premarital sex has become widely accepted among young people. Sexual behavior is now considered an individual responsibility [5].

Stigmatization of HIV and AIDS is a serious problem throughout China. Many people living with HIV/AIDS are afraid to tell anyone about their status. If they choose to tell people in their surroundings they risk losing their social support and jobs and being discriminated against in other ways [6].

\section{HIV and AIDS in Hubei}

Hubei province is in central China, with a population of 65 million. The majority of the people live in rural areas. Together with Yunnan, Guangxi, Anhui and Guangdong, Hubei accounts for 83 per cent of the total reported number of HIV cases in the country [2]. Hubei province is estimated to have around 45,000 HIV positives. This high number is explained by commercial blood selling several years ago. The epidemic started among the poor population in rural areas. Transmission owing to blood selling is now under control but the virus keeps spreading through sexual relations and mother-to-child transmission [6]. The epidemic in Hubei, as elsewhere in China, has spread from high risk groups to the general population [2]. 


\section{Wuhan University}

Wuhan University, in the capital of Hubei, is a key university directly under the administration of the Education Ministry of the People's Republic of China. The university was founded in 1893 and has 29 colleges and various branches of learning. The number of students enrolled is $53,000,18,000$ of whom are postgraduates [7]. Students come to attend the university from all over China and from many foreign countries.

\section{Objective}

The HIV virus is spreading rapidly throughout China in the general population. Young people are considered to be a group at high risk. Therefore it is essential to assess their knowledge, attitudes and risk behavior when planning preventive strategies.

\section{PARTICIPANTS AND METHODS}

\section{Sampling}

Undergraduate students at Wuhan University were selected, using stratified cluster sampling, to answer a questionnaire during spring 2008. The participants studied at different faculties, including Medicine, Information Science, Engineering, Social Science, Humaniores Science and at the Faculty of Science. The three main groups are presented in Table 1.

Table 1. The 868 Participating Students by University Year

\begin{tabular}{|c|c|c|c|c|c|c|}
\hline & \multicolumn{2}{|c|}{$\begin{array}{c}\text { Chinese } \\
\text { Medical } \\
\text { Students }\end{array}$} & \multicolumn{2}{c|}{$\begin{array}{c}\text { Chinese } \\
\text { Non-Medical } \\
\text { Students }\end{array}$} & \multicolumn{2}{c|}{$\begin{array}{c}\text { Foreign } \\
\text { Medical } \\
\text { Students }\end{array}$} \\
\hline Year & Number & $\%$ & Number & $\%$ & Number & $\%$ \\
\hline \hline First & 120 & 45.3 & 45 & 13.0 & 89 & 34.9 \\
\hline Second & 70 & 26.4 & 127 & 36.7 & 82 & 32.2 \\
\hline Third & 70 & 26.4 & 164 & 47.4 & 81 & 31.8 \\
\hline Fourth & 1 & 0.4 & 10 & 2.9 & 3 & 1.2 \\
\hline Fifth & 4 & 1.5 & & & & \\
\hline
\end{tabular}

All participating students were informed of the general objectives of the study and that they could choose to withdraw at any time. In order to ensure the confidentiality of the information provided, they were advised not to write their names on the questionnaires.

\section{Questionnaire}

To assess the knowledge, attitudes and risk behaviors regarding HIV and AIDS, a self-administrated questionnaire was used. The questionnaire consisted of 47 questions divided into four categories: General questions, Questions about HIV/AIDS, Private life and Questions about work situation. The questions were in English but with some of the words translated into Chinese to clarify. To avoid linguistic misunderstandings, the Chinese students were able to direct their questions to both English and Chinese speaking students during the completion of the form. The time required to fill out the questionnaire was approximately 20 30 minutes.

The questionnaire used in the study has been previously tested in other international studies [8,9]. Modifications were made to adjust the questionnaire to Chinese culture and customs, such as religious and ethnical groups.

\section{Interviews}

For deeper understanding, 14 interviews were conducted. Eight of them were with Chinese students and six were with foreign students. The students attended different departments at the university, 8 were men and 6 were women. The age range was 19 to 45 .

All students were informed that their participation was voluntary and that they did not have to answer questions they found too private. The Chinese students could choose to do the interview in Chinese or in English. All interviews with the foreign students were conducted in English.

The interview questions were based on interviews performed in similar studies [8,9]. The interviewed student was asked to talk freely about subjects such as general knowledge about HIV/AIDS, attitudes towards infected persons, sexuality and the possibility of a future epidemic in China. Each interview took approximately 30 minutes.

\section{Data Analysis}

To enter and analyze the data, Epidata version 3.1 and the Statistical Package for Social Sciences (SPSS) version 13.0 were used. Data obtained were evaluated by frequency and percentage ratios and Chi-square $\left(\mathrm{X}^{2}\right)$ test. A p-value of $<0.05$ was considered significant.

\section{RESULTS}

\section{Sample Characteristics}

A total of 868 questionnaires were collected. The questionnaires were gathered from three different groups: Chinese medical students $(n=265)$, Chinese non-medical students $(n=346)$ and foreign medical students $(n=257)$; $50.3 \%$ were women, $49.2 \%$ were men and $0.5 \%$ did not give their sex. Ages ranged from 17 to 34 years and the mean age was 20.4 .

In relation to the question of ethnicity, $87.4 \%$ of the Chinese students answered Han Chinese. The other Chinese students were divided between Tuija (4.1\%), Miao (1.0\%), Hui $(1.5 \%)$ and other ethnicity $(6.1 \%)$. One student did not answer this question. Of the foreign students, $69.3 \%$ came from India, 5.2\% from Nepal and 3.1\% from Pakistan. Most students stated that they had no religion (61.3\%). $11.5 \%$ were Muslim and 10.0\% were Christians.

Among all respondents, $814(93.8 \%)$ were single, 31 $(3.6 \%)$ lived with a partner, $6(0.7 \%)$ were married, $3(0.3 \%)$ were widowed, $1(0.1 \%)$ was divorced and $4(0.5 \%)$ had other marital status. Nine (1\%) students did not answer. Only $7(0.8 \%)$ students answered that they had children.

More than half of the students $(59.8 \%)$ were majoring in Medicine, $10.9 \%$ in Social Science, $8.4 \%$ in Humaniores Science, $7.4 \%$ in Engineering, $7.0 \%$ in Information Science 
and $6.5 \%$ studied at the Faculty of Science. The non-medical students had generally been studying for longer than the medical students $(\mathrm{p}<0.001)$, (Table 1).

\section{Sources of HIV/AIDS Information}

Of the 868 students, all but 9 had heard of HIV/AIDS, $52.6 \%$ stated that they had known about it for five to ten years. The most common source of first information $(50.9 \%)$ was media, $40.2 \%$ had first heard of it in school. There were no significant differences between the three main student groups or gender. Eighty-eight percent answered that they had been given information about HIV/AIDS before entering university and $71.8 \%$ had received information at university. Of the foreign medical students, $97.2 \%$ had had information before university compared to $85.0 \%$ of the Chinese medical students and $89.5 \%$ of the Chinese non-medical students $(\mathrm{p}<0.003)$. Only $74.1 \%$ of the foreign students had received information at university, which was significantly fewer than among both the Chinese medical students $(88.5 \%)$ and the Chinese non-medical students $(84.9 \%)(\mathrm{p}<0.002)$.

Fifty-two percent did not feel that the information had been sufficient. In relation to the medical students, nonmedical students answered to a larger extent that the received information had not been sufficient $(51.7 \%$ versus $39.9 \%$, $\mathrm{p}<0.02)$. The most requested additional information was about current circumstances and spreading tendencies of AIDS all over the world (Table 2). Of the Chinese medical students, $53.5 \%$ reported that the information had been sufficient.

\section{General Knowledge of HIV/AIDS}

Seven hundred forty-one (95.4\%) students answered that there is a difference between HIV and AIDS. When asked to specify, $659(75.9 \%)$ students could distinguish HIV as a virus and AIDS as an infectious disease; $84.5 \%$ of the Chinese medical students and $80.2 \%$ of the foreign medical students knew of the difference and could specify it correctly. Significantly fewer Chinese non-medical students $(66.2 \%)$ could make the same distinctions $(\mathrm{p}<0.001)$.
Religion had no significant influence on the awareness of HIV.

The main route of transmission was considered to be sexual intercourse $(40.4 \%)$ while $35.5 \%$ believed it to be by blood transfusion. However, there was a significant difference of opinion between foreign students and Chinese students $(\mathrm{p}<0.001)$. More than half of the Chinese students, both medical $(53.5 \%)$ and non-medical $(50.8 \%)$, stated blood transfusion as the main route of transmission, while the foreign medical students $(81.9 \%)$ stated sexual intercourse.

Knowledge regarding transmission routes is presented in Fig. (1). To some of the questions, there were significant differences between the three main groups. Regarding whether kissing is a route of transmission, more Chinese than foreign students believed it to be so (Chinese medical students $29.5 \%$, Chinese non-medical students $32.7 \%$ versus foreign medical students $27 \%, \mathrm{p}<0.01)$. The Chinese students believed that sharing needles is a route of transmission to a less extent than foreign students (Chinese medical students $91.6 \%$, Chinese non-medical students $92.4 \%$ versus foreign medical students $98.0 \%, \mathrm{p}<0.04)$. Fifty-eight percent of the Chinese non-medical students answered that breastfeeding can spread the disease, which was significantly lower than the Chinese medical students $(64.5 \%)$ and the foreign medical students $(70.4 \%)(\mathrm{p}<0.04)$. Thirty-nine percent of both the Chinese medical students and the Chinese non-medical students believed that the disease can be spread by mosquitoes while only $15.5 \%$ of the foreign medical students believed so $(\mathrm{p}<0.001)$. Regarding legal blood/plasma donation, $38.3 \%$ of the Chinese medical students stated this as a route of transmission, which was significantly higher than both the Chinese non-medical students $(28.0 \%)$ and the foreign medical students $(28.9 \%)$ $(p<0.03)$. Of the female students, 96.3\% recognized sharing needles as a route of transmission, compared with $91.1 \%$ of the male students $(p<0.01)$. Breastfeeding was believed to spread the virus by $69.2 \%$ of the women and $57.7 \%$ of the men; $66.4 \%$ of the women and $56.6 \%$ of the men recognised kissing as being harmless and $66.3 \%$ of the men and $55.7 \%$

Table 2. Requested Additional Information About HIV/AIDS

\begin{tabular}{|c|c|c|c|c|c|}
\hline Requested information & $\begin{array}{l}\text { Chinese Medical } \\
\text { Students }\end{array}$ & $\begin{array}{l}\text { Chinese Non- } \\
\text { Medical Students }\end{array}$ & $\begin{array}{l}\text { Foreign Medical } \\
\quad \text { Students }\end{array}$ & $\begin{array}{l}\text { Total } \\
\text { Number }\end{array}$ & $\begin{array}{c}\text { Tota } \\
\%\end{array}$ \\
\hline $\begin{array}{l}\text { Current circumstances and spreading tendencies of AIDS all } \\
\text { over the world }\end{array}$ & 28 & 44 & 32 & 104 & 12.0 \\
\hline Prevention-control measures & 25 & 53 & 22 & 100 & 11.5 \\
\hline Research progress & 23 & 29 & 23 & 75 & 8.6 \\
\hline $\begin{array}{l}\text { The spreading circumstances of HIV/AIDS in close } \\
\text { surroundings }\end{array}$ & 11 & 20 & 11 & 42 & 4.8 \\
\hline Routes of transmission & 4 & 21 & 5 & 30 & 3.5 \\
\hline Other information & 6 & 2 & 4 & 12 & 1.4 \\
\hline Harmful results & 4 & 4 & 1 & 9 & 1.0 \\
\hline Total & 101 & 173 & 98 & 372 & 42.9 \\
\hline No answer & 164 & 173 & 159 & 496 & 57.1 \\
\hline Total & 265 & 346 & 257 & 868 & 100 \\
\hline
\end{tabular}




\section{Routes of transmission}

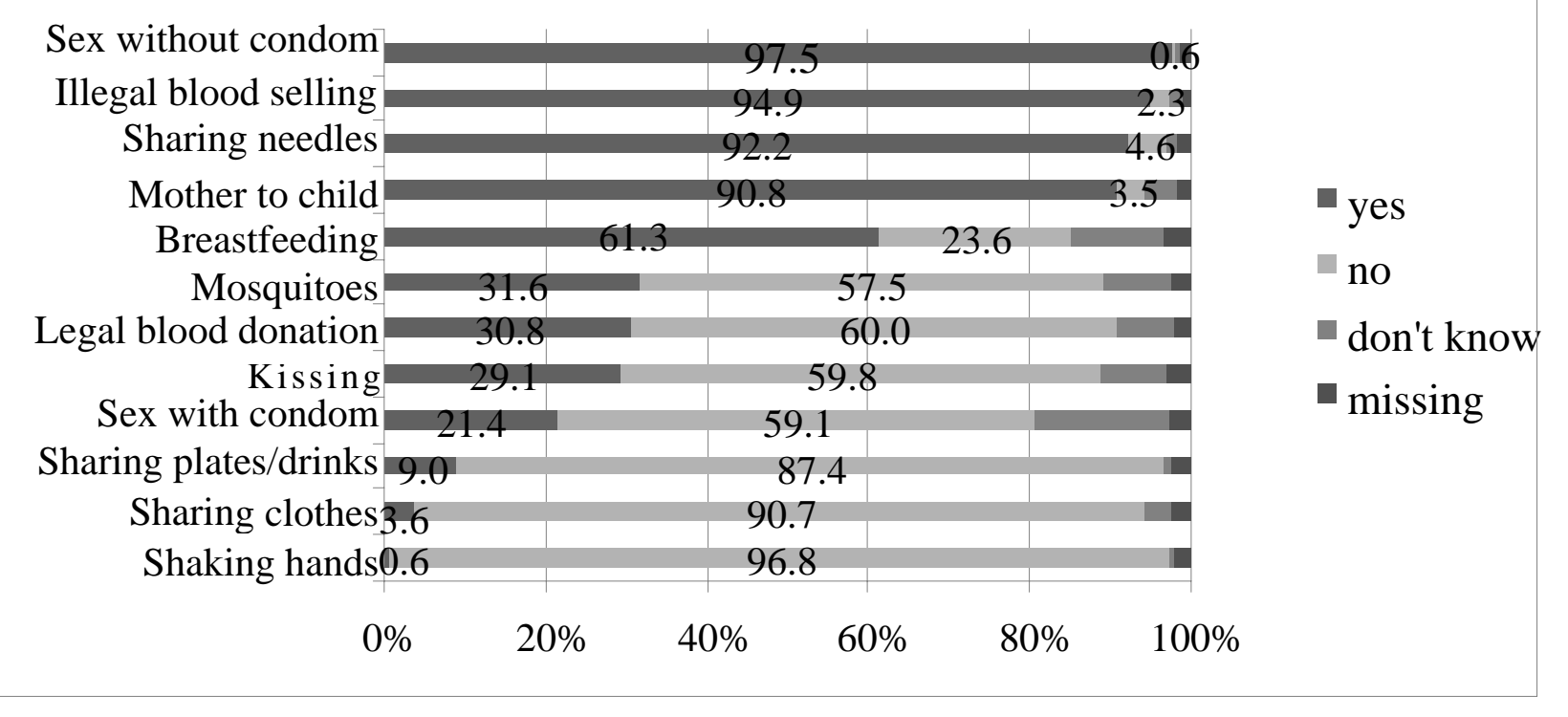

Fig. (1). Believed routes of HIV transmission.

of the women answered that sex with a condom does not spread the disease. Ninety-six (11.1\%) students answered all the questions correctly, with no significant differences between the three main groups but significantly more women $(14.9 \%)$ than men $(7.3 \%)$ answered completely correctly $(\mathrm{p}<0.001)$. There were no significant differences in knowledge of routes of transmission between sexually active and non-sexually active students.

The majority of the foreign medical students (73.9\%) wrote that they knew how to diagnose HIV, while only $29.1 \%$ of the Chinese medical students and $18.8 \%$ of the Chinese non-medical students answered that they knew $(p<0.001)$. There was a significant increase of knowledge between the first and second year of university studies, from $65 \%$ to $84 \%$ among the foreign medical students ( $p<0.001$ ), but not among the Chinese medical students.

Students' knowledge in the area of treatment was measured by three questions. To the first question, if a person with HIV/AIDS can be completely cured, $84.1 \%$ answered no and only $4.3 \%$ answered yes. The Chinese medical students had significantly less knowledge about the absence of a cure than the two other groups; $8.8 \%$ of the Chinese medical students believed that there is a cure for AIDS while only $1.7 \%$ of the Chinese non-medical students and $3.2 \%$ of the foreign medical students gave the same answer $(\mathrm{p}<0.02)$. The majority $(85.6 \%)$ of the students answered that HIV/AIDS medications slows down the progression of AIDS. Fifty-four percent did not know if there are any other treatments besides antiretroviral treatment, $27.9 \%$ answered that there are no other treatments and $15.6 \%$ answered that there are.

The life expectancy for an HIV positive person was generally underestimated. Without medicine, the students estimated the life expectancy to a mean of 5.1 years (range 0-30 years) and with medicine 11.4 years (range 1-65 years). There were no significant differences between the three main groups.

\section{Attitudes}

It was found that $37.8 \%$ of the students would not treat a person with HIV differently from others, $31.8 \%$ answered that they did not know and $27.1 \%$ that they would treat an infected person differently. Among those who answered yes, many wrote that they would be more considerate and concerned about the infected person's health. All 14 students interviewed answered that they would not treat a person with HIV differently from others. All of the interviewed foreign students and some of the Chinese students believed that an HIV positive person would be treated differently by the general public in China because of fear and lack of knowledge.

A majority (58.8\%) of the students believed that there are special groups that are more likely to be infected with HIV than others. Common examples were prostitutes and drug addicts. The Chinese medical students answered that there are special groups to larger extent than the other two groups of students $(p<0.03)$, and the Chinese non-medical students answered yes more often than the foreign medical students $(\mathrm{p}<0.001)$.

\section{Private Life}

Regarding with whom the students could talk about HIV/AIDS, $73.7 \%$ answered friends. The second most common answer was mother $(32.8 \%)$, followed by health personnel (31.6\%) and partner (31.0\%). There were significant differences between women and men: $76.9 \%$ of the female students said they could talk to their friends, $41.2 \%$ to their mother and $30.7 \%$ to their father while only $70.5 \%$ of the male students could talk to their friends, $24.6 \%$ to their mother and 
$22.7 \%$ to their father $(p<0.04)$. Out of seven alternatives of people to talk to, the mean number of options stated was 2.14 (range 0-7). The mean value for women was 2.26 and for men $2.01(\mathrm{p}<0.03)$. Twenty-five $(2.9 \%)$ students answered that they did not have anyone to talk with.

Only 25 students knew a person diagnosed with HIV/AIDS, 15 of them were foreign medical students, which was significantly more than for the Chinese students $(p<0.01)$.

The vast majority $(86.3 \%)$ of the students had not had any sexual contact. Eighty (9.2\%) students answered that they were sexually active. Thirteen of them were Chinese medical students, 43 were Chinese non-medical students and 24 were foreign medical students. Only 73 of the 80 answered the question about number of sexual partners and among them, 7 wrote 0 partners. Of the sexually active students, the foreign medical students had had a significantly higher mean number of sexual partners $(2.62$, range $0-8)$ than the Chinese medical students $(0.78$, range $0-1)$ and the Chinese non-medical students $(1.12$, range $0-3)(\mathrm{p}<0.003)$. Religion had no significant relation to the number of sexual contacts.

The mean age of first sexual contact among the 80 sexually active students was 19.3 years of age (range 10-24). There were no significant differences between the three main groups or gender. Of the sexually active students, $49 \%$ answered that they would ask a new partner about previous partners, 23\% would ask a new partner to take an HIV test, and $28 \%$ would ask them to test for other sexually transmitted diseases.

Nine (1\%) of the students admitted to having paid money for sexual favours: seven men and two women. Three students $(0.3 \%)$, two women and one man, answered that they had been paid money for sex.

Only three women and one man stated that they had had homosexual contacts. Therefore we can not evaluate if homosexuality increase the risk behavior.
The opinion that both partners have equal responsibility for the use of condom was shared by $67.5 \%$ of the students, $16.9 \%$ reckoned that the man has the main responsibility and $2.9 \%$ the woman. Among the foreign medical students, $88.6 \%$ answered that both share equal responsibility, which was a higher percentage as compared with $73.5 \%$ of the Chinese medical students and $73.4 \%$ of the Chinese non-medical students $(\mathrm{p}<0.001)$.

Three hundred ninety-five (45.5\%) of the respondents stated that they would like to be tested for HIV. Fewer foreign medical students than Chinese students, $32.8 \%$ compared to $53.1 \%$, wanted to take an HIV test $(p<0.01)$. This could be explained by the fact that most of them had already been tested, for security reasons, when they first came to China.

Their mother was the person most of the students said they would tell if they tested positive for HIV. Female students were more likely than male students to tell their mothers $(p<0.003)$ and men were more likely than women to tell other relatives and co-workers $(\mathrm{p}<0.04)$, (Fig. 2). The mean number of selected options was 1.87 .

Eighty-seven percent of the students stated that they would not have children if they knew they were infected with HIV.

\section{Future Epidemic in China}

Of the respondents, $42.3 \%$ answered that there is a risk of a future HIV epidemic in China, $14.6 \%$ did not think so, $39.2 \%$ did not know and $3.9 \%$ did not answer. There were significant differences between the foreign medical students and the two Chinese groups $(\mathrm{p}<0.003)$, (Fig. 3). Explanations of why there is a risk for a future epidemic were ignorance and stigmatization of HIV/AIDS. During the interviews, the foreign students pointed out that there has not been enough attention paid to HIV/AIDS in China and that the government has not taken proper actions. This opinion was not shared by most of the Chinese students, who were more hopeful that a future epidemic could be prevented.

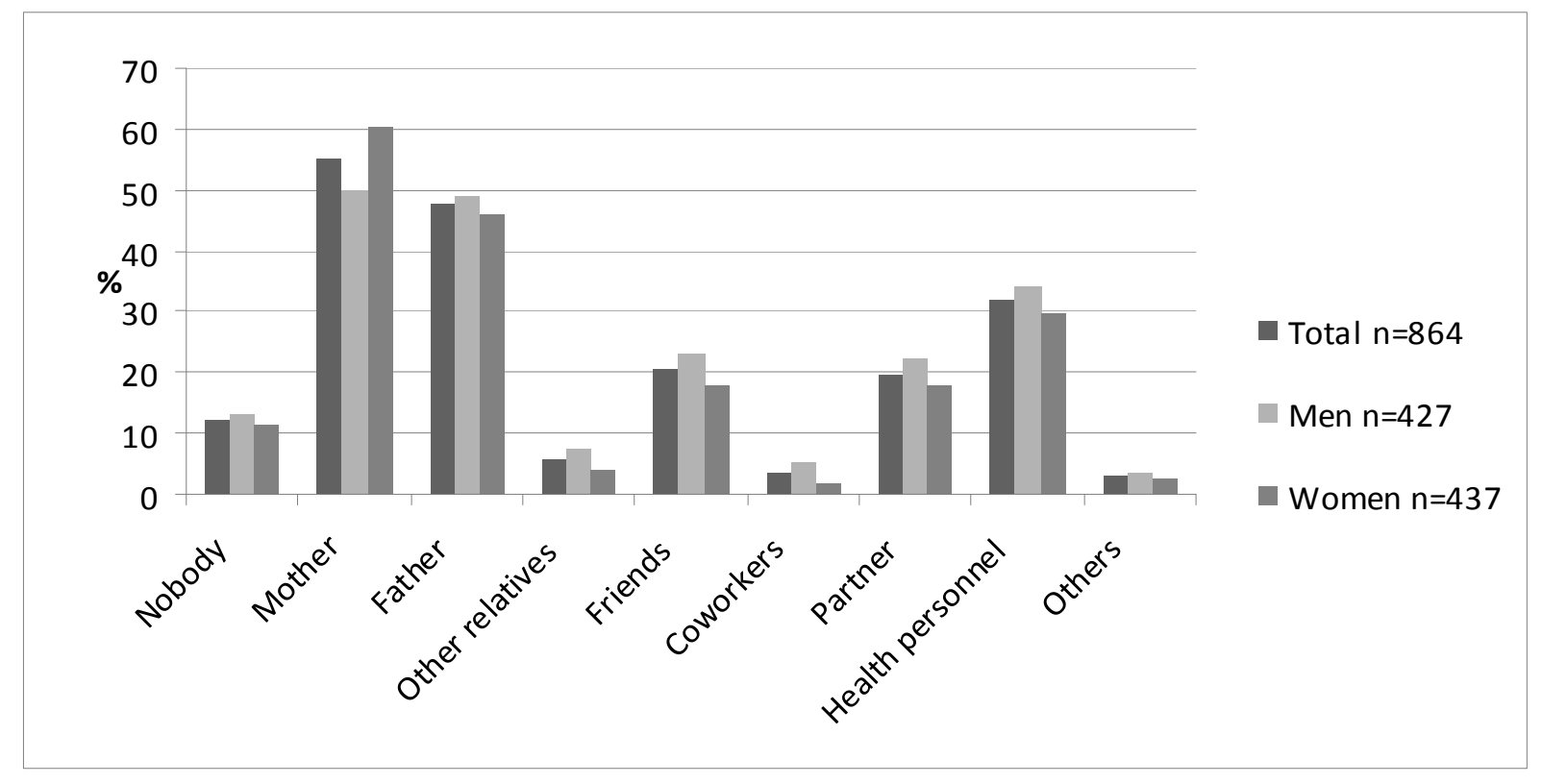

Fig. (2). People the students would tell if they found out they were HIV positive. 


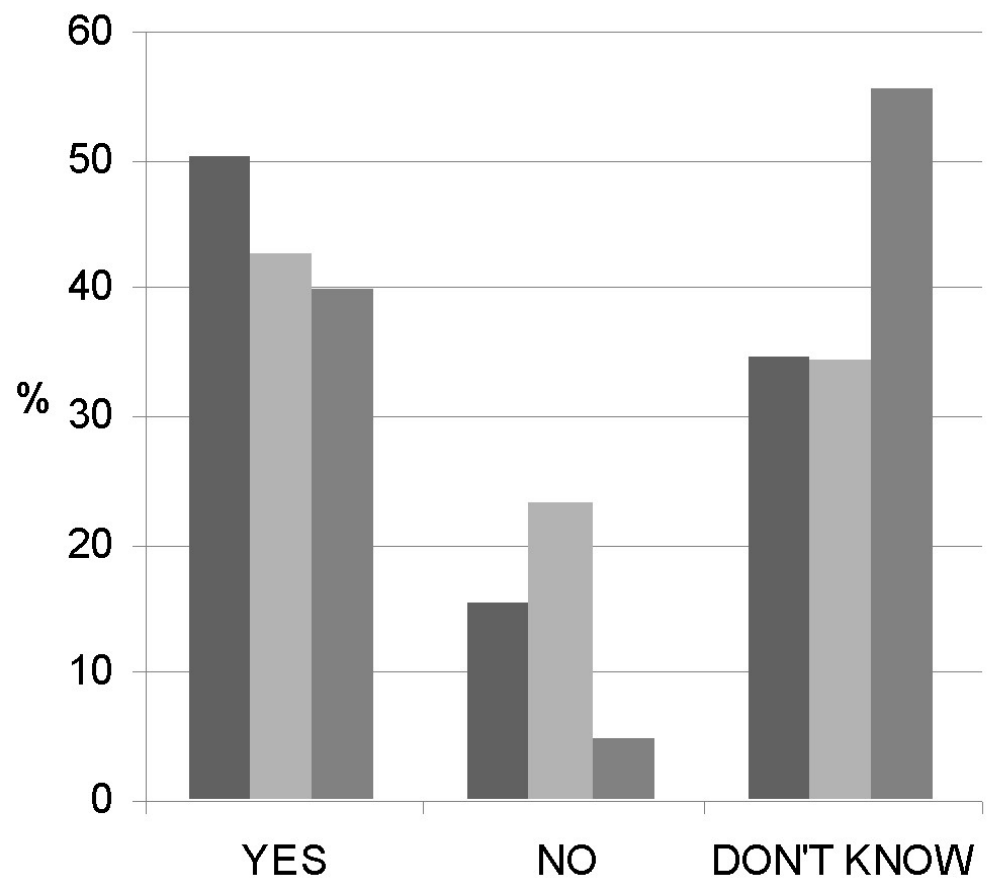

- Chinese medical students $n=249$

Chinese non-medical students $\mathrm{n}=334$

Foreign medical students $\mathrm{n}=251$

Fig. (3). Believed risk for a future HIV/AIDS epidemic in China.

\section{LIMITATIONS}

The fact that Wuhan University has a very good academic reputation could be seen as a limitation when the study is compared to studies performed at other universities in China.

The questionnaire was written in English with difficult words translated into Chinese. Still, some of the Chinese students found it difficult to comprehend. To the two questions about whom to talk to about general information of HIV/AIDS and whom to tell if infected, the similar alternatives were unfortunately in a different order in the questionnaire.

\section{DISCUSSION}

\section{Sources of HIV/AIDS Information}

In the study, it was found that $99 \%$ of the students had heard of HIV/AIDS and that the media were the most common sources of information. This coincides with previous studies performed at Wuhan University in 2006 and Xinjiang Medical University in $2004[8,10]$. Only 40.2\% reported that their first information was received at school. The Chinese students stated in the interviews that they had had little or no sexual education or information about STD's at school. They all wished that they had been better informed at school and agreed that there is a great need for more sexual education among young pupils in China. The same conclusion was drawn when AIDS and sex education in China were assessed in 2001[11]. To further emphasize that pupils in China are in need of more education, the study showed that the foreign medical students had received significantly more information before coming to university.

\section{General Knowledge of HIV/AIDS}

The knowledge regarding the distinction between HIV and AIDS was good. Three quarters of the students could correctly distinguish HIV from AIDS. This differs greatly from results in a similar study performed in Kazakhstan, where only $17.6 \%$ answered correctly [9].

There was a significant difference between all Chinese students and the foreign medical students in regard to what they believed to be the main route of transmission in China today. The majority of the Chinese students answered blood transfusion, while the foreign medical students almost exclusively answered sexual intercourse. These results can be explained by the fact that blood transfusions were once the main route of transmission in China, especially in Hubei province. In 1997, the Chinese government issued new laws and regulations, and therefore transmission via blood donations is now considered to be under control [12]. Sexual intercourse has just recently become the dominant mode of spread $[2,5]$. It can be assumed that the reason the foreign students answered sexual intercourse was that this is the main route of transmission throughout the world [13].

Most of the respondents knew the main routes of transmission. Compared to a study among Chinese college students in 2000, the awareness among the Wuhan students were better [14]. Still, about one third of the students had misconceptions concerning mosquitoes and kissing. The same misconceptions were found among students in Xinjiang [8]. Overall, the female students had better knowledge than the male students of the routes of transmission.

Almost eighty percent of the students answered that there are ways to protect oneself against sexually transmitted 
HIV/AIDS. Most wrote in answer to the open corollary question: by condom use. This is in line with findings in a previous study at the same university where more than ninety percent knew that condom use prevents STDs [10].

An unexpected result was that the foreign medical students knew to a much larger extent than the Chinese medical students how to diagnose HIV. When asked to specify, most of the foreign students also gave more exact specifications, such as ELISA and WESTERN BLOT, while the Chinese students often wrote blood test or HIV test. This is surprising since the two groups study medicine at the same university.

More than eighty percent of the students knew that HIV/AIDS cannot be cured and that medication only slows down the progression. Looking at similar studies, the level of knowledge was higher among the Wuhan students $[8,9]$. In answer to the question of whether there were other treatments besides antiretroviral medicines, the Chinese medical students more often than the other student groups in the study answered that there were, referring to Chinese traditional medicines. There are not, to date, studies to provide sufficient information about the effects of Chinese traditional medicines on HIV [15].

\section{Attitudes}

Stigmatization of HIV/AIDS in China has been a major reason for the difficulties in reducing the rate of spread [1]. It has been shown that the degree of stigmatising beliefs is related to levels of income and education [16]. Among the Wuhan University students in the study, who are considered to be well educated, more than fifty percent answered either that they would or did not know if they would treat a person with HIV differently from others. This could be an indication that stigmatisation is still a substantial problem even among the well educated population. However, it must be taken into account that many students wrote that they would treat an infected person differently in a positive way.

Compared with students in Kazakhstan, the Wuhan students believed to a larger extent that there are special groups that are more likely to be infected with HIV than others. Prostitutes and drug addicts were pointed out in both studies [9]. This is in agreement with conclusions drawn when subpopulations of importance for HIV spread were investigated in 2005 [17].

\section{Private Life}

The vast majority of the students talk to their friends about general information regarding HIV/AIDS. It was much more common to talk to friends than parents, which is an indication that the subject is not openly discussed. However, more female than male students felt that they could talk to their parents. These findings are consistent with previous studies $[8,14,18]$. Chinese society is very traditional, and matters like HIV/AIDS are considered private. Fear and shame were considered reasons not to discuss subjects related to sexuality by many of the interviewed students.

It can be concluded that the Wuhan University students in the study did not have extensive sexual risk behavior.
Only $8.1 \%$ were sexually active, which is comparable with findings concerning other students in China $[8,10,19]$. The age of first sexual contact was also comparable $[8,10]$. Attitudes towards premarital sex have become more tolerant in the last few years in China $[5,18]$. In the interviews, students agreed that there has been a change of attitudes but that behavior has not yet changed.

A total of $67.5 \%$ of the students believed that both partners have equal responsibility for the use of condoms during sexual intercourse. This is twice as many as students in Xinjiang [8], probably due to cultural differences between the Chinese regions. Almost half of the students in the study wanted to take an HIV test. Many gave as a reason that they want to be healthy or just to be sure. This might be an indication of lack of knowledge with regard to the routes of transmission since it is not likely that they had been exposed to the virus. These results are also similar to the results concerning the Xinjiang students [8].

\section{Future Epidemic in China}

There is a great risk of a future epidemic in China according to the students. The main reasons for their opinion were the lack of knowledge in the general population and the change in sexual behavior among young people in China. Many believe that an epidemic can be prevented, but only if the government take more enforceable actions.

In conclusion, the Wuhan University students in the study had a positive and accepting attitude towards people living with HIV, and no extensive risk behavior. The level of knowledge varied between the three main groups and to some extent between genders. Overall, the level of knowledge was found to be moderate, and there is room for improvement. In China, there is a need for more sexual education both before and at university. It is especially important to increase the overall knowledge among the men and to give all increased awareness of the possibilities to prevent mother to child transmission of HIV and to reduce stigma by a deeper understanding on how HIV is not transmitted.

\section{ACKNOWLEDGEMENTS}

We would like to thank Professor Jing Sun for sharing her statistical knowledge and Professor Chunhong Wang for all her support.

To all the students at Professor Tan's laboratory and other friends, thank you for all the time and energy that you put into the study, and for making our stay in Wuhan unforgettable.

\section{REFERENCES}

[1] Wu Z, Rou K, Cui H. The HIV/AIDS epidemic in China: history, current strategies and future challenges. AIDS Educ Prevent 2004;16(Suppl A): 7-17.

[2] State Council AIDS Working Committee Office, UN Theme Group on AIDS in China: A Joint Assessment of HIV/AIDS Prevention, Treatment and Care in China. Available at: http://data.unaids. org/pub/Report/2008/china_2008_country_progress_report_en.pdf [Accessed April 7, 2008].

[3] Zhang KL, Ma SJ. Epidemiology of HIV in China. Intravenous drug users, sexworkers, and large mobile populations are high risk groups. BMJ 2002; 324: 803-4. 
[4] Gorbacha PM, Ryan C, Saphonn V, Detels R. The impact of social, economic and political forces on emerging HIV epidemics. AIDS 2002; 16 (Suppl 4): S35-43.

[5] Zhang K, Beck EJ. Changing sexual attitudes and behavior in China: Implications for the spread of HIV and other sexually transmitted diseases. AIDS Care 1999; 11(5): 581-9.

[6] Médecins Sans Frontières. Available at: http://www.msf.org.au/sto ries/twproject/2004/036twp.shtml [Accessed April 8, 2008].

[7] Wuhan University. Available at: http://www.whu.edu.cn/en/about /index.html [Accessed April 14, 2008].

[8] Lönn E, Sahlholm K, Maimaiti R, Abdukarim K, Andersson R. A traditional society in change encounters HIV/AIDS: knowledge, attitudes and risk behavior among students in Northwestern China. AIDS Patient Care STDs 2007; 21(1): 51-60.

[9] Hansson L, Stockfelt L, Urazalin M, Andersson R, Ahlm C. HIV/AIDS awareness and risk behavior among students in Kazakhstan: a cross sectional survey. BMC Int Health Hum Rights 2008; 8: 14

[10] Tan X, Pan J, Zhou D, Wang C, Xie C. HIV/AIDS knowledge, attitudes and behaviors assessment of Chinese students: a questionnaire study. Int J Environ Res Public Health 2007; 4(3): 248-53.

[11] Gao Y, Lu ZZ, Shi R, Sun XY, Cai Y. AIDS and sex education for young people in China. Reprod Fertile Dev 2001; 13: 729-37.

[12] Wu Z, Rou K, Detels R. Prevalence of HIV infection among former commercial plasma donors in rural eastern China. Health Policy Plan 2001; 16(1): 41-6.
[13] UNAIDS. 2006 report on the global AIDS epidemic: A UNAIDS 10th anniversary special edition. Available at: http://www.unaids. org/en/KnowledgeCentre/HIVData/GlobalReport [Accessed April $25,2008]$.

[14] Li X, Lin Ch, Gao Z, et al. HIV/AIDS knowledge and implications for health promotion programs among Chinese college students: geographic, gender and age differences. Health Promot Int 2004; 19 (3): 345-56.

[15] Portsmouth S, Stebbing J, Keyi X, Jianping Z, Guohua P. HIV and AIDS in the Peoples Republic of China: a collaborative review. Int J STD AIDS 2003; (14): 757-61.

[16] Liu H, Li X, Stanton B, et al. Relations of sexual risks and prevention practises with individuals' stigmatising beliefs towards HIV infected individuals: an exploratory study. Sex Transm Infect 2005; 6 (81): 511-6.

[17) Qian ZH, Vermund SH, Wang N. Risk of HIV/AIDS in China: subpopulations of importance. Sex Transm Infect 2005; 81: 442-7.

[18] Wang B, Li X, Stanton B, et al. Sexual attitudes, pattern of communication, and sexual behavior among unmarried out-ofschool youth in China. BMC Public Health 2007; 7: 189.

[19] Huang J, Bova C, Frennie KP, Rogers A, Williams AB Knowledge, attitudes, behaviors, and perceptions of risk related to HIV/AIDS among Chinese university students in Hunan, China. AIDS Patient Care STDS 2005; 11(19): 769-77. 